thebmi

\title{
Editorials
}

\section{The NHS carbon reduction strategy}

BMJ 2009; 338 doi: http://dx.doi.org/10.1136/bmj.b326 (Published 28 January 2009) Cite this as: BMJ 2009;338:b326

\author{
Ian Roberts, professor of epidemiology and public health, position \\ ${ }^{1}$ London School of Hygiene and Tropical Medicine, London WC1E 7HT
}

lan.Roberts@Ishtm.ac.uk

The battle plan is written, but will the NHS go to war with its emissions?

Climate change kills at least 150000 people each year, and the suffering it causes will increase as we continue to pollute the atmosphere.1 The effects of climate change on health will continue to be concentrated in the poorest parts of the world and will mainly affect children.2 The NHS is responsible for $25 \%$ of England's public sector emissions-more than 18 million tonnes of carbon dioxide a year. The NHS carbon reduction strategy for England, "Saving Carbon, Improving Health," was published this week; it sets out how the NHS aims to lead the way to a low carbon world.3

The strategy builds on a strong evidence base-the groundbreaking NHS carbon footprinting exercise published in 2008.4 However, the strategy quickly runs into its first obstacle. The largest part (60\%) of the NHS carbon footprint is from procurement-the manufacture and transport of goods and services purchased by the NHS from other organisations. Pharmaceuticals contribute most to procurement emissions, being responsible for 4 million tonnes of carbon dioxide a year. The strategy is weak in this area, saying that "research will be undertaken into the carbon footprint of pharmaceuticals within the NHS to better understand this and to inform actions to produce significant reductions." This sounds like a dodge.

The NHS could reduce drug related carbon emissions either by reducing the carbon intensity of drug production or by reducing drug use. The NHS already pays a high price for drugs-much of the basic research that underpins drug development is funded by the public, which enables the drug industry to cream off the profitable part.5 6 Because the global atmosphere also bears some of the costs, the real cost of drugs is even higher than the monetary cost. The NHS can and should use its purchasing power to press the drug industry to decarbonise.

The Department of Health should also give the prevention of disease the priority that it deserves but currently lacks. For example, the United Kingdom is predicted to be a predominantly obese society by 2050.7 If we want to avoid a situation where more than half of the population is taking carbon intensive drugs to suppress their appetite or to prevent their bodies from absorbing fat, then we will need to do much better than Change4Life, the new "lifestyle revolution" recently launched by the Department of Health to stem rising obesity. 8 
The government would have us believe that obesity is a personal failing by weak willed people who make the wrong selections from a wealth of lifestyle and diet choices. However, a decade of research into obesity shows that fatness is an environmental problem not a personal foible.9 People in the UK are getting fatter firstly because they are surrounded by low priced, heavily marketed, energy dense food, and secondly because fossil fuel powered transport means they move their bodies less than ever before. Serious government action to stem the oversupply of food and encourage sustainable transport (walking and cycling) would reduce the carbon footprint of the NHS and the whole of British society as well.

The strategy points out that the NHS is one of the largest purchasers of food in the UK, and that in future patients, visitors, and staff can look forward to healthy low carbon menus with much less meat, dairy produce, and eggs. Evidence shows that as far as the climate it concerned, meat is heat.10 Providing land for cattle grazing results in deforestation, and the methane released from animal manure and enteric fermentation is a powerful greenhouse gas. Eating less meat would also have health benefits, such as reducing the risk of colon cancer.10

The strategy says that all trusts should have approved plans for tackling NHS related travel. The strategy recommends a flat reimbursement rate for NHS business mileage, regardless of the mode of transport (car, cycle, or foot), and it urges that travel related NHS emissions are monitored. The strategy also asserts that greater efforts should be made to reduce NHS related travel, and that the delivery of health care will move closer to home. There are also important key actions on reducing water consumption and avoiding waste.

The enthusiasm of everyone in the NHS workforce will be enlisted to deliver the strategy through an ambitious low carbon workforce development programme. All NHS organisations "should" sign up to the NHS good corporate citizen assessment model, should produce a sustainable development management plan, and should embed carbon reduction in their financial mechanisms. The lack of any "musts" is concerning. The strategy is garnished with a rousing quotation from Prime Minister Gordon Brown about our "historic and world changing" mission to build a low carbon economy, a quotation worthy of any wartime Churchill. As a battle plan, the NHS carbon reduction strategy is an excellent start, and the NHS Sustainable Development Unit must be congratulated for its leadership. But only time will tell whether the NHS will actually go to war with its emissions and win.

\section{Notes}

Cite this as: BMJ 2009;338:b326

\section{Footnotes}

- Competing interests: None declared.

- Provenance and peer review: Commissioned; not externally peer reviewed.

\section{References}

1. McMichael A, Woodruf R, Hales S. Climate change and human health: present and future risks. Lancet 2006;367:859-69.

2. Haines A, Smith KR, Anderson D, Epstein PR, McMichael AJ, Roberts I, et al. Policies for accelerating access 
to clean energy, improving health, advancing development, and mitigating climate change. Lancet2007;370:1264-81.

3. NHS Sustainable Development Unit. Saving carbon, improving health. 2009. London: NHS Sustainable Development Unit.

4. NHS England Carbon Emissions. Carbon footprint study 2008. London: NHS Sustainable Development Unit, Sustainable Development Commission. Stockholm: Environment Institute.

5. Angell M. The truth about the drug companies: how they deceive us and what to do about it. New York: Random House, 2004.

6. Hinsliff G. Health chief attacks drug giants over huge profits. Observer 17 Aug 2008. www.guardian.co.uk/uk/2008/aug/17/pharmaceuticals.nhs.

7. Foresight. Tackling obesities: future choices. 2007. www.foresight.gov.uk/OurWork/ActiveProjects/Obesity/Obesity.asp.

8. Department of Health. Change4Life. www.nhs.uk/Change4Life/Pages/default.aspx.

9. Swinburn BA. Obesity prevention: the role of policies, laws and regulations. Aust N Z Health Policy2008;5:12.

10. McMichael A, Powles J, Butler C, Uauy R. Food, livestock production, energy, climate change, and health. Lancet 2007;370:1253-63. 